\title{
Risk Behaviors and STI Prevalence Among People with HIV in EI Salvador
}

\author{
G. Paz-Bailey ${ }^{*}, 1,2,3$, N. Shah ${ }^{3}$, J. Creswell ${ }^{1,2}$, M.E. Guardado ${ }^{1}$, A.I. Nieto ${ }^{4}$, M.C. Estrada ${ }^{5}$, \\ R. Cedillos ${ }^{6}$, J.M. Pascale ${ }^{7}$ and E. Monterroso ${ }^{3}$
}

\author{
${ }^{I}$ Training Programs in Epidemiology and Public Health Interventions Network (TEPHINET) Central American office, \\ Guatemala City, Guatemala \\ ${ }^{2}$ Centre for Health Studies, Del Valle University, Guatemala City, Guatemala \\ ${ }^{3}$ Centers for Disease Control and Prevention, Atlanta, GA, USA \\ ${ }^{4}$ Ministry of Health, San Salvador, El Salvador \\ ${ }^{5}$ United States Agency for International Development, San Salvador, El Salvador \\ ${ }^{6}$ Hospital Rosales, San Salvador, El Salvador \\ ${ }^{7}$ Gorgas Memorial Institute for Health Studies, Panama City, Panama
}

\begin{abstract}
To date, there are no studies from El Salvador among people with HIV to inform prevention programs. We conducted a study in El Salvador in 2008 among people with HIV using audio computer-assisted interviews on risk behaviors and access to health care. Blood was tested for syphilis and herpes simplex type 2 (HSV-2). Active syphilis was defined as RPR titer $\geq 1: 8$. Genital specimens were tested for other sexually transmitted infections (STI) by PCR. We evaluated factors associated with unprotected sex with last stable partner of HIV-negative or unknown status among those reporting a stable partner. A total of 811 HIV-positive individuals participated: 413 men and 398 women. Prevalence of Chlamydia and gonorrhea was low $(\leq 1 \%)$, while prevalence of other STI was high: Mycoplasma genitalium (14\%), syphilis (15\% seropositivity, active syphilis 3\%) and HSV-2 (85\%). In multivariate analysis, disclosing HIV status to partner (OR 0.2, 95\% CI: 0.1-0.3, p <0.001), participation in HIV support groups (OR 0.3, 95\% CI: 0.1-0.8, p=0.01), easy access to condoms (OR 0.4, 95\% CI: 0.2-0.9, $\mathrm{p}=0.04$ ) were protective factors for unprotected sex. Reporting a casual partner in the last 12 months (OR 3.6, 95\% CI: 1.5-8.5, p=0.004). and having an STI (OR 2.6, 95\% CI:1.3-5.5, p=0.02) were associated with an increased odds of unprotected sex. Prevention interventions among HIV-positives in El Salvador should focus on increasing condom access, promoting HIV disclosure and couples testing and reducing the number of partners. The positive role of support groups should be used to enhance behavioral change.
\end{abstract}

Keywords: El Salvador, HIV, AIDS, Prevention, People living with HIV, Condoms, Sexually transmitted infections.

\section{INTRODUCTION}

With less than one percent of the adult population estimated to be HIV-positive, El Salvador is a low HIV prevalence country, but the virus remains a significant threat in high-risk communities [1]. Since the first case was detected in 1984, 22,210 HIV/AIDS cases have been reported in the country [1]. Based on official statistics, heterosexual sex is the main route of HIV transmission, accounting for $95 \%$ of HIV cases while less than $5 \%$ of cases are among men who have sex with men (MSM) [2]. However, information on sexual practices is not consistently collected and stigma and discrimination may preclude patients from accurately reporting their sexual orientation and risk behaviours. Also, it is estimated that approximately $40 \%$ of HIV cases are not reported to the National HIV Program [3].

*Address correspondence to this author at the 1600 Clifton Road, Atlanta Georgia 303333 MS E-46, USA; Tel: +1 4046394451; Fax: +4046398640; E-mail: gmb5@cdc.gov
Although self-awareness of HIV infection has been shown to reduce risk behaviors among many people with HIV $[4,5]$, some continue to engage in unsafe sex [4, 6-8]. Unsafe sex places partners at risk for HIV transmission and also increases the personal risk of contracting sexually transmitted infections (STI). Factors associated with unsafe practices include lack of knowledge of partners' HIV status, alcohol and illicit drug consumption, heterosexual sex, and race/ethnicity [9-11]. Stable partnership, especially in heterosexual couples, has also been shown to be associated with unsafe practices, even after taking into account HIV sero-concordance $[12,13]$. Moatti et al. [14] showed that episodes of unprotected sex occur in similar proportions with both regular and occasional partners. However, in Moatti's study respondents who declared multiple sexual partners were more likely to have always used condom than those who only had one single partner during the previous 6 months. In addition, among HIV-infected patients who lived in a stable relationship, more than two thirds did not know the serostatus of their partner and this was associated with a greater chance of unsafe sex [14]. 
Approaches to HIV prevention have typically focused on individuals who are HIV-negative or whose serostatus is unknown [15]. Based on recent findings on the impact of antiretroviral treatment (ART) to prevent HIV transmission [16] broadening treatment access will continue to be a public health priority, which will have the potential to bring more individuals with HIV within the reach of additional health care, support and prevention services. Antiretroviral treatment for prevention will have to be complemented with other successful strategies for prevention with HIV-positives [17]. Prevention strategies for positives will need to be grounded in an understanding of risk behaviors and their context [18]. Currently, little is known about the risk behavior profiles of people with HIV in many areas where ART has recently become available. Information is scarce on risk behaviors among people with HIV outside the context of controlled trials or from regions other than Africa $[12,19]$ and no studies have been published in Central America.

ART became available in El Salvador in 2001. By 2010, antiretroviral treatment for HIV has been provided to 5,205 patients in El Salvador in 16 comprehensive HIV treatment centers, equivalent to $64.5 \%$ coverage of those eligible for HIV treatment [20]. We present results from the first behavioral survey of people with HIV in El Salvador recruited from comprehensive HIV treatment centers. The main purposes of this study were to: 1) describe the population of sexually active HIV-positive men and women in El Salvador, and 2) assess factors associated with unprotected sex with stable and casual partners.

\section{METHODS}

\section{Study Population and Enrollment}

Participants were men and women with HIV infection recruited between March and September of 2008 using consecutive sampling from the HIV clinics at the country's two major public hospitals-- Rosales and Zacamil in San Salvador. Participants were also recruited from HIV peer support groups at these and six other public hospitals providing ART in El Salvador's most populated cities: San Salvador, Santa Ana and San Miguel; and referred to the study sites in Rosales and Zacamil Hospitals for enrolment. According to Ministry of Health data, these public hospitals account for $80 \%$ of patients on ART in the country [20]. Individuals with a previous diagnosis of HIV aged 18 years or older who reported having anal or vaginal sex in the past 12 months and who were willing and able to provide written informed consent were eligible to enroll in the study. No additional biological testing was done to confirm HIV infection. Screening to establish eligibility and avoid repeat respondents was performed by the treatment physician and the study coordinator.

Participants were asked to complete a behavioral questionnaire and/or provide specimens for STI testing. Interviews were conducted by peer outreach workers from HIV prevention organizations, who were trained on study procedures, consent administration, interviewing techniques, interview instruments and confidentiality. Study questionnaires were based on standardized survey instruments [21]. They included face-to-face interviews for the non-sensitive sections of the questionnaire and audio computer-assisted self interviews (ACASI) for the more sensitive sections. Prior to the start of the interview participants were trained with a series of mock questions on how to use ACASI. All interviews were conducted in a private setting. Interviews elicited information on demographics; substance abuse; sexual behavior in the past 12 months including heterosexual and homosexual contacts with stable, casual, and commercial partners, condom use; HIV diagnosis; services received as part of HIV monitoring and treatment; CD4 counts, antiretroviral therapy and problems with adherence; HIV knowledge and perceived HIV-related stigma and discrimination. We collected additional information on the last casual and stable partner on: consistent condom use in the last 12 months, condom use at last sex, condom use during the last 10 sexual vaginal or anal intercourses, disclosure of HIV status to partner, discussion of STI and HIV issues with partners in the last 12 months and HIV status of partner.

A sample size of 400 men and 400 women was calculated based on feasibility of recruitment, ability to detect differences between the current and follow-up surveys among all participants and by sex, given $80 \%$ power and a level of significance of $5 \%$. With 400 participants and a design effect of two, differences of $10 \%$ or greater can be detected between the current and follow-up survey, assuming, conservatively, a dichotomous indicator with a baseline level of $50 \%$. This sample size allows us to estimate a $50 \%$ prevalence of consistent condom use with stable partners with 95\% confidence intervals (CI) 45-55.

\section{Clinical and Laboratory Procedures}

Following the interviews, participants were offered STI counseling, a physical exam to evaluate for signs and symptoms of STI, and a pelvic exam. Vaginal swab samples (female participants), urine (male) and blood samples were collected by trained staff. Urine and vaginal samples were screened using a multiplex real time polymerase chain reaction (PCR) for bacterial STI, including Chlamydia trachomatis, Neisseria gonorrhoea, Trichomonas vaginalis, and Mycoplasma genitalium. Blood samples were tested for syphilis, based on reactive rapid plasma regain (RPR) and positive Treponema particle-agglutination assay (TPPA), and for herpes simplex virus type 2 (HSV-2), with HerpeSelect ${ }^{\circledR}$ (Focus Technologies, Cypress, CA). Participants received and STI test results card and were told to return in four weeks for results. STI test results and free treatment for participants with STI symptoms or laboratory-diagnosed infection were provided through public facilities linked with the study.

Syphilis and HSV-2 serologies were done at the National Reference Laboratory in San Salvador, El Salvador. Quality control and PCR testing was done at the Gorgas Memorial Institute in Panama City, Panama. Quality control for PCR was provided by the Centers for Disease Control Laboratory in Atlanta, USA.

The ethical review board of Rosales National Hospital (RNH) in San Salvador approved the study protocol. The Centers for Disease Control and Prevention-Global AIDS Program Associate Director for Science reviewed and approved the protocol. 


\section{Measures}

A stable partner was defined as someone the participant has known for more than two months, with who he/she has an emotional bond with and with whom he/she has regular sex, such as boyfriend, spouse, significant other, or life partner. A casual partner referred to a partner with whom the respondent was not living or married to, only had sex with occasionally and did not exchange money for sex. Commercial partners were those who were given money or gifts in exchange for sex. Active syphilis was defined as an RPR titer $\geq 1: 8$ and a reactive TPPA result. To assess knowledge on HIV transmission the Joint United Nations Program on HIV/AIDS (UNAIDS) indicator was used [22], that included the following questions: 1 . Can having sex with only one faithful, uninfected partner reduce the risk of HIV transmission? 2. Can using condoms reduce the risk of HIV transmission? 3. Can a healthy-looking person have HIV? 4. Can a person get HIV from mosquito bites? 5. Can a person get HIV by sharing a meal with someone who is infected? Having correct knowledge was defined as providing the correct answer to all five questions among respondents who gave answers. To assess if patients had unprotected sex in the last 12 months we considered variables on consistent condom use, condom use during last sexual encounter and condom use during the last 10 sexual acts for stable and casual partners separately. Unprotected sex was defined as not using condoms during last sex or less than $100 \%$ of times. The main outcomes evaluated for the study were: 1 ) Unprotected sex with last stable partner of HIV-negative or unknown status; 2) Unprotected sex with last casual partner. Knowledge of HIV status of casual partners was rare and evaluating unprotected sex with last casual partner of HIVnegative or unknown status provided similar results to the second outcome presented.

\section{Data Analysis}

Descriptive analysis was stratified by sex. Chi-square tests were used to test the overall difference between patient groups for categorical variables when expected cell counts were five or more, and the Fisher's exact test otherwise. Ttests were used to test differences in continuous variables when normally distributed, and the Wilcoxon Rank Sum test otherwise.

Logistic regression models were developed to evaluate the outcomes described above. Variables with p-values of 0.10 or less in bivariate analysis were included in the models. A variable was retained in each model if the p-value obtained from a likelihood ratio test was less than 0.05 . The final models were adjusted for sex and study site. Associations are reported as odds ratios (OR) with 2-sided pvalues and $95 \%$ confidence intervals (CI). Likelihood-ratio tests were used to compare alternate model specifications. Statistical analyses were performed using SAS version 9.1 (SAS Institute, Cary, North Carolina, USA).

\section{RESULTS}

Of 1,185 people invited to participate in the study 52 were not eligible (4\%) and $322(27 \%)$ declined to participate. Reasons for declining to participate included not having the time $(179,56 \%)$, not interested in the study $(99,31 \%)$ and other $(44,14 \%)$. The reasons for non-eligibility included not having had sex in the last year $(\mathrm{n}=27)$, being under age $(\mathrm{n}=20)$ and having had participated in the study previously $(n=5)$. A total of 811 HIV-positive individuals were enrolled in the study, 413 men and 398 women. Of these, 59\% were from Hospital Rosales, 21\% from Hospital Zacamil and 20\% from support groups from six other hospitals treating HIV patients. The median age was 35 years (Inter-quartile range [IQR]: 29-43). Most participants had little formal education $(45 \%)$ and $78 \%$ had a monthly income of less than $\$ 180$ a month (the minimum monthly wage in El Salvador) (Table 1).

Having ever been forced into sex during their lifetime was reported by $12 \%$ of men and $30 \%$ of women $(p=0.001)$, and in the last month by $2 \%$ and $5 \%$ respectively $(\mathrm{p}=0.32)$. Most participants reported a stable partner $(55 \%$ of men and $75 \%$ of women, $p<0.001$ ) and for both men and women half reported their stable partner was HIV-positive. Only $10 \%$ of men and $13 \%$ of women did not know the HIV status of their stable partner. A high proportion $(85 \%)$ of participants discussed HIV and STI issues with their stable partners, showing that there was some communication with partners on HIV-related matters. A casual partner in the last 12 months was reported by $44 \%$ of men and $23 \%$ of women $(p<0.001)$. A total of 131 men $(32 \%)$ reported having had sex with a male partner (MSM) in the last 12 months. Of these, $31(24 \%)$ also reported a female partner. During the last 12 months, selling sex was reported by $5 \%$ of men and $3 \%$ of women $(\mathrm{p}=0.32)$ and buying sex by $12 \%$ and $0.5 \%$, respectively $(\mathrm{p}<0.001)$. Few reported drug use and $9 \%$ reported alcohol use in the last 30 days.

\section{Condom Use and Condom Access}

There were no major differences in condom use by sex or by type of partner. Overall, consistent condom use was $68 \%$ for stable partners, $65 \%$ with casual partners and $63 \%$ with sex workers. Unprotected sex with the last stable partner was not different with HIV-positive stable partners $(23 \%)$ and partners of HIV-negative or unknown status $(21 \%, \mathrm{p}=0.58)$. Similarly, with the last casual partner unprotected sex was $26 \%$ with known HIV-positive and 31\% with casual partners of HIV-negative or unknown status $(\mathrm{p}=0.58)$.

In terms of condom access, $85 \%$ reported that it was easy to obtain a condom. The most commonly reported places to obtain condoms were pharmacies (72\%) and public hospitals or clinics (43\%). Among the reasons for using condoms $92 \%$ reported to prevent HIV and STI, only $4 \%$ reported they used condom to prevent pregnancies.

\section{Services and HIV care}

Of participants, $25 \%$ had a recent HIV diagnosis $(12$ months or less) and $71 \%$ were receiving ART. Overall, $87 \%$ (706) had a CD4 count done in the last 12 months. Of 358 who knew their CD4 count result the mean CD4 count was 408 cells $/ \mathrm{mm}^{3}$ (95\% CI: $385-432$ ), and was not different for men (374 cells $/ \mathrm{mm}^{3}, 95 \%$ CI: $\left.354-415\right)$ and women (413 cells $/ \mathrm{mm}^{3}, 95 \%$ CI: 399-474) $(\mathrm{p}=0.10)$.

\section{STI Prevalence}

Overall, $85 \%$ were sero-positive for HSV-2, $0.3 \%$ had gonorrhea and $1 \%$ chlamydial infection. Syphilis seroprevalence was $21 \%$ among men and $10 \%$ among women 
Table 1. Description of the Study Population, HIV-Positive Men and Women, EI Salvador, 2008

\begin{tabular}{|c|c|c|c|c|c|c|c|c|c|}
\hline $\begin{array}{ll} & \text { Variables } \\
\text { Demographics } & \end{array}$ & \multicolumn{3}{|c|}{ Total N=811 } & \multicolumn{3}{|c|}{ Men $N=413$} & \multicolumn{3}{|c|}{ Women $\mathrm{N}=398$} \\
\hline Education ${ }^{*}$ & 803 & & & 409 & & & 394 & & \\
\hline None/primary & & 364 & 45.3 & & 136 & 33.3 & & 228 & 57.9 \\
\hline Some university & & 56 & 7.0 & & 48 & 11.7 & & 8 & 2.0 \\
\hline Income $^{*}$ & 806 & & & 410 & & & 396 & & \\
\hline$\leq \$ 180$ US dollars & & 631 & 78.3 & & 294 & 71.7 & & 337 & 85.1 \\
\hline$>\$ 181$ US dollars & & 175 & 21.7 & & 116 & 28.3 & & 59 & 14.9 \\
\hline Gay & & 64 & 15.8 & & 64 & 15.8 & -- & -- & -- \\
\hline Other & & 8 & 2.0 & & 8 & 2.0 & & & \\
\hline \multicolumn{10}{|l|}{ Behaviors } \\
\hline Has stable partner ${ }^{*}$ & 804 & 518 & 64.4 & 408 & 223 & 54.7 & 396 & 295 & 74.5 \\
\hline HIV-positive stable partner & 516 & 261 & 50.6 & 223 & 115 & 51.6 & 293 & 146 & 49.8 \\
\hline Disclosed HIV status to stable partner ${ }^{*}$ & 506 & 408 & 80.6 & 217 & 164 & 40.2 & 289 & 244 & 59.8 \\
\hline Casual partners in the last 12 months $^{*}$ & 800 & 270 & 33.8 & 407 & 178 & 43.7 & 393 & 92 & 23.4 \\
\hline Same sex partner in the last 12 months* & 811 & 132 & 16.3 & 413 & 131 & 31.7 & 398 & 1 & 0.3 \\
\hline \multicolumn{10}{|l|}{ Consistent condom use in the last 12 months } \\
\hline With stable partner & 573 & 390 & 68.1 & 259 & 179 & 69.1 & 314 & 211 & 67.2 \\
\hline With casual partner & 270 & 175 & 64.8 & 178 & 120 & 67.4 & 92 & 55 & 59.8 \\
\hline With sex workers & 48 & 30 & 62.5 & 46 & 28 & 60.8 & 2 & 2 & 100.0 \\
\hline Unprotected sex with last stable partner of HIV-negative or unknown status & 518 & 64 & 12.3 & 223 & 26 & 11.7 & 295 & 38 & 12.9 \\
\hline Unprotected sex with last casual partner & 270 & 77 & 28.5 & 178 & 45 & 25.3 & 92 & 32 & 34.8 \\
\hline \multicolumn{10}{|l|}{ Services and HIV care } \\
\hline Easy condom access & 797 & 674 & 84.6 & 408 & 359 & 88.0 & 389 & 315 & 81.0 \\
\hline Time since HIV diagnosis of $\leq 12$ months & 815 & 200 & 24.5 & 415 & 108 & 26.0 & 400 & 92 & 23.0 \\
\hline On ART & 781 & 551 & 70.6 & 398 & 273 & 68.6 & 383 & 278 & 72.6 \\
\hline HIV knowledge & 815 & 464 & 56.9 & 415 & 231 & 55.7 & 400 & 233 & 58.3 \\
\hline Participated in HIV support groups* & 806 & 279 & 34.6 & 412 & 109 & 26.5 & 394 & 170 & 43.2 \\
\hline
\end{tabular}

Note: STI=sexually transmitted infection, ART=antiretroviral treatment.

$* \mathrm{P}$ value $<0.05$ for differences between men and women.

$(\mathrm{p}<0.001)$, and active syphilis was $6 \%$ and $0.5 \%$ respectively $(\mathrm{p}<0.001)$. Active syphilis was higher among MSM $(10 \%)$ than heterosexual men $(3 \%) \quad(\mathrm{p}<0.001)$. Mycoplasma genitalium was higher among women $(20 \%)$ than men $(9 \%)$ $(\mathrm{p}<0.001)$, as was trichomoniasis at $9 \%$ and $0.3 \%$, respectively $(\mathrm{p}<0.001)$ (Table 2$)$. 
Table 2. STI Prevalence Among HIV-Positive Men and Women, EI Salvador, 2008

\begin{tabular}{|c|c|c|c|c|c|c|c|c|c|}
\hline STI & $\mathbf{N}$ & $\mathbf{n}$ & $\%$ & $\mathbf{N}$ & $\mathbf{n}$ & $\%$ & $\mathbf{N}$ & $\mathbf{N}$ & $\%$ \\
\hline Syphilis $^{*}$ & 760 & 116 & 15.3 & 381 & 78 & 20.5 & 379 & 38 & 10.0 \\
\hline Active syphilis (TPPA + RPR $\geq 1: 8)^{*}$ & 760 & 23 & 3.0 & 381 & 21 & 5.5 & 379 & 2 & 0.5 \\
\hline Chlamydia trachomatis ${ }^{*}$ & 745 & 9 & 1.2 & 361 & 0 & 0 & 379 & 9 & 2.3 \\
\hline Neisseria gonorhoeae & 745 & 2 & 0.3 & 361 & 0 & 0 & 383 & 2 & 0.5 \\
\hline Mycoplasma genitalium ${ }^{*}$ & 744 & 107 & 14.4 & 361 & 32 & 8.9 & 382 & 75 & 19.6 \\
\hline Trichomonas vaginalis $^{*}$ & 745 & 37 & 5.0 & 361 & 1 & 0.3 & 383 & 36 & 9.4 \\
\hline
\end{tabular}

Note: RPR=reactive rapid plasma reagin; TPPA=Treponema particle-agglutination assay.

${ }^{*} \mathrm{P}$ value $<0.05$ for differences between men and women.

\section{Variables Associated with Unprotected Sex in Multivariate Analysis}

We evaluated variables associated with unprotected sex with the last stable partner of HIV-negative or unknown status and with the last casual partner.

\section{Unprotected Sex with Last Stable Partner of HIV- Negative or Unknown Status}

Disclosing HIV status to their partner (OR 0.2, 95\% CI: $0.1-0.3, \mathrm{p}<0.001$ ), participating in HIV support groups (OR $0.3,95 \% \mathrm{CI}: 0.1-0.8, \mathrm{p}=0.01$ ), easy condoms access (OR 0.4, 95\% CI: $0.2-0.9, \mathrm{p}=0.04)$ were associated with a decreased odds of unprotected sex with a stable partner of HIVnegative or unknown status. Reporting a casual partner in the last 12 months (OR 3.6, 95\% CI: 1.5-8.5, p=0.004), and having an STI (OR 2.6, 95\% CI: 1.3-5.5, p=0.02) were associated with an increased odds of unprotected sex (Table 3).

\section{Unprotected Sex with Last Casual Partner}

Participants with higher education (OR 0.3, 95\% CI: $0.2-$ $0.6, \mathrm{p}=0.001)$, with an HIV diagnosis of more than 12 months (OR 0.4, 95\% CI: 0.2-0.7, p=0.003), and with easy access to condoms (OR 0.4, 95\% CI: 0.2-0.9, p=0.03), had decreased odds of unprotected sex with the last casual partner. Having an HIV-positive casual partner was not associated with unprotected sex (OR 0.8, 95\% CI: 0.4-1.7, $\mathrm{p}=0.58)$.

\section{DISCUSSION}

This is the first study among HIV-infected people in El Salvador to evaluate HIV risk behaviors and STI prevalence. The study demonstrated that it was feasible to recruit large numbers of HIV patients, collect biological specimens, and to administer interviews through ACASI despite low educational levels. Importantly, we found a high prevalence of some STI such as HSV-2, syphilis, and Mycoplasma genitalium, while condom use was equally low with stable and casual partners. Surveillance strategies are needed to periodically collect information from HIV-positive individuals; these data are essential to monitor trends in behaviors and assess coverage of ART and other interventions.

Women were different to men in many aspects. They had less formal education, lower income and higher reports of sexual abuse and discrimination. Although they were less likely to report risk behaviors such as drug use, casual sex, and more likely to disclose their HIV status to their partners, they had similar reports of low condom use compared to men.

Men, and in particular MSM in this study, had a high prevalence of syphilis and active syphilis. Since 1998, outbreaks of syphilis among MSM have been documented in several countries [23-27]. In these outbreaks about 50\% to $60 \%$ of MSM with early syphilis are HIV infected [28-33]. High syphilis and HIV co-infection rates within sexual networks may enhance the spread of both sexually transmitted infections [25, 34, 35]. Importantly, one third of men reported a male partner in the last year. Based on official statistics only $5 \%$ of HIV cases in the country are considered MSM [2]. Efforts should be made to improve the collection of risk behaviors in routine surveillance through training of providers and health workers on correct reporting, and implementing interventions to reduce stigma and discrimination. Accurate surveillance information is key to improve evidence based allocation of resources for prevention, especially in the context of El Salvador were prevention for most at risk populations is underfunded [3638].

Access to condoms was an important factor associated with unprotected sex with both stable and casual partners. A few private initiatives in El Salvador have been implemented to increase condom access for female sex workers and MSM [39]; but more needs to be done through the public health system to guarantee condom access to HIV-positives already in care at the main public hospitals in the country. Structurallevel interventions have been shown to be efficacious in other settings in increasing condom use, increasing condom acquisition or condom carrying among a wide range of populations [40], and should be evaluated for El Salvador.

As in previous studies we found that individuals who disclosed their HIV status to their partners were more likely to practice safe sex [41-43]. Couples testing and counseling 
Table 3. Variables Associated with Unprotected Sex with Last Stable and Casual Partners in Bivariate and Multivariate Analysis Among Men and Women Living with HIV, El Salvador 2008

\begin{tabular}{|c|c|c|c|c|c|c|c|c|}
\hline & \multicolumn{4}{|c|}{$\begin{array}{l}\text { Unprotected Sex with Last Stable Partner of } \\
\text { HIV-Negative or Unknown Status N=518 }\end{array}$} & \multicolumn{4}{|c|}{$\begin{array}{l}\text { Unprotected Sex with Last } \\
\text { Casual Partner } N=\mathbf{2 7 0}\end{array}$} \\
\hline & $\%$ & $\begin{array}{l}\text { Unadjusted } \\
\text { OR }(95 \% \text { CI })\end{array}$ & $\begin{array}{c}\text { Adjusted } \\
\text { OR }(95 \% \text { CI })\end{array}$ & $\begin{array}{l}\text { ADJUSTED } \\
\text { p-Values }\end{array}$ & $\%$ & $\begin{array}{l}\text { Unadjusted } \\
\text { OR }(95 \% \mathrm{CI})\end{array}$ & $\begin{array}{c}\text { Adjusted } \\
\text { OR }(95 \% \text { CI })\end{array}$ & $\begin{array}{l}\text { Adjusted } \\
\text { p-Values }\end{array}$ \\
\hline \multicolumn{9}{|l|}{ Education } \\
\hline$\leq$ Primary School & & & & & 43.3 & 1.0 & 1.0 & 0.001 \\
\hline \multicolumn{9}{|c|}{ Disclosure of HIV to partner } \\
\hline No & 28.9 & 1.0 & 1.0 & $<0.001$ & 31.2 & 1.0 & & \\
\hline Yes & 7.9 & $0.2(0.1-0.4)$ & $0.2(0.1-0.3)$ & & 25.4 & $0.7(0.4-1.4)$ & & \\
\hline \multicolumn{9}{|l|}{ Casual partner } \\
\hline$\leq 12$ months & & & & & 41.5 & 1.0 & 1.0 & 0.003 \\
\hline$>12$ months & & & & & 24.5 & $0.5(0.3-0.8)$ & $0.4(0.2-0.7)$ & \\
\hline \multicolumn{9}{|c|}{ Participation in HIV support groups } \\
\hline No & 16.1 & 1.0 & 1.0 & 0.01 & 28.0 & 1.0 & & \\
\hline Yes & 4.8 & $0.3(0.1-0.6)$ & $0.3(0.1-0.8)$ & & 30.9 & $1.1(0.6-2.0)$ & & \\
\hline \multicolumn{9}{|l|}{ Condom access } \\
\hline Difficult & 22.7 & 1.0 & 1.0 & 0.04 & 50.0 & 1.0 & 1.0 & 0.03 \\
\hline Easy & 9.4 & $0.4(0.2-0.6)$ & $0.4(0.2-0.9)$ & & 25.0 & $0.3(0.2-0.7)$ & $0.4(0.2-0.9)$ & \\
\hline
\end{tabular}

Note: $\mathrm{STI}=$ sexually transmitted infections, $\mathrm{CI}=$ confidence intervals, $\mathrm{OR}=$ odds ratios. Models were adjusted for sex and study site. Variables considered for the multivariate model for unprotected sex with last stable partner of HIV-negative or unknown status were: disclosure of HIV status to partner, time since HIV diagnosis, alcohol use, participation in HIV support groups, condom access, having a casual partner and STI. Variables considered for the multivariate model for unprotected sex with last casual partner were: education, time since HIV diagnosis, condom access, and forced sex.

might be an appropriate strategy to increase disclosure and also identify more HIV-positive individuals in order to link them to care and prevention. We also found that support groups are playing a positive role on prevention of high risk behaviors, and might be effective in supporting behavioral change including HIV disclosure, reduction of casual sex and increased condom use. People who were aware they were HIV infected for more than one year had safer practices with casual partners, which may indicate that changes in behavior with knowledge of HIV status might be improved over time, as in other settings [41].

This study had several limitations. The design of the study was cross-sectional, therefore causality could not be established. Our findings are based on self reported behavior that could therefore be biased. The use of ACASI may lead to an increased, but not necessarily complete, reporting of stigmatized behaviors. Since recruitment took place in public hospitals, the study may not be representative of all HIVpositive individuals in El Salvador. However, the vast majority of HIV-positive patients in care $(>90 \%)$ are seen in government facilities. We included the major hospitals providing care to HIV-positives and we believe the results provide a good overview of the situation for HIV-positive individuals in care in the country. Our analysis was limited to the most recent stable and casual partner. We did not perform formal network analysis and out findings are not generalizable to participants' networks or to the HIVpositive population in El Salvador.

In conclusion, there is a pressing need to strengthen positive prevention interventions in El Salvador. Interventions that have been shown to be effective among HIV-positives are those integrating theory-based prevention within routine medical care and services, addressing aspects of mental health and antiretroviral therapy adherence in addition to HIV-risk behavior and providing HIV-positive individuals with the necessary skills for successful risk reduction $[44,45]$. Given that the potential of an intervention delivered to an HIV-positive person may prevent multiple HIV infections prevention with HIV-positives offers a unique opportunity for significantly reducing HIV transmission. To cast the widest possible net, interventions should include early identification of HIV-positives through 
broad-based HIV testing initiatives especially within high risk populations.

\section{ACKNOWLEDGEMENTS}

We would like to express our gratitude to the Ministry of Health of El Salvador for leading this study and providing permission to use government health facilities. We would especially like to thank the staff at the participating hospitals and the study participants who made this survey possible. We have furthermore to thank Ron Ballard and Lisa Steele for providing quality control for laboratory testing at the Centers for Disease Control and Prevention STD Laboratory and providing technical advice. Our appreciation to Licenciada Nelly Arguera from the National Laboratory of the Ministry of Health in El Salvador for processing all serological tests and Juan Castillo from de Gorgas Memorial Institute for Health Studies in Panama City for processing the PCR tests. Thanks to doctors Julio Armero, Guillermo Garay, Rodrigo Siman and Elizabeth Rodriguez for their contribution to the protocol and valuable support during data collection.

This work was supported by Tephinet Inc. through a cooperative agreement (\#6D43GH000014-05) from the United States Centers for Disease Control and Prevention. Funding was also provided by the United States Agency for International Development, the Ministry of Health of El Salvador, the World Bank and the Network for Research and Training in Tropical Diseases in Central America (NeTropica) under the project No 06-R-2010.

\section{DISCLAIMER}

The findings and conclusions in this paper are those of the authors and do not necessarily represent those of the Centers for Disease Control and Prevention or the World Health Organization.

\section{CONFLICT OF INTEREST}

The authors confirm that this article content has no conflicts of interest.

\section{REFERENCES}

[1] Joint United Nations Program on HIV/AIDS (UNAIDS). AIDS Epidemic Update: December 2008. Geneva, Switzerland: UNAIDS, 2008. Report No.: UNAIDS/06.29E.

[2] Ministerio de Salud Publica y Asistencia Social (MSPAS). Situacion de VIH/SDA en El Salvador. San Salvador, El Salvador: Ministerio de Salud de El Salvador 2008.

[3] Creswell J, Armero J, Rosental J, Monterroso E. Using Lot Quality Assurance to Evaluate Sub-Notification of HIV/AIDS in E1 Salvador. San Salvador, El Salvador: de; Valle University of Guatemala and Ministry of Health, El Salvador 2006.

[4] Centers for Disease Control and Prevention (CDC). High-risk sexual behavior by HIV-positive men who have sex with men--16 sites, United States, 2000-2002. MMWR Morb Mortal Wkly Rep 2004; 53(38): 891-94.

[5] Marks G, Crepaz N, Senterfitt JW, Janssen RS. Meta-analysis of high-risk sexual behavior in persons aware and unaware they are infected with HIV in the United States: implications for HIV prevention programs. J Acquir Immune Defic Syndr 2005; 39(4): 446-53.

[6] Kalichman SC, Kelly JA, Rompa D. Continued high-risk sex among HIV seropositive gay and bisexual men seeking HIV prevention services. Health Psychol 1997; 16(4): 369-73.

[7] Wohl AR, Johnson DF, Lu S, Frye D, Bunch G, Simon PA. Recent increase in high-risk sexual behaviors among sexually active men who have sex with men living with AIDS in Los Angeles County. J Acquir Immune Defic Syndr 2004; 35(2): 209-11.

[8] McGowan JP, Shah SS, Ganea CE, et al. Risk behavior for transmission of human immunodeficiency virus (HIV) among HIVseropositive individuals in an urban setting. Clin Infect Dis 2004; 38(1): 122-7.

[9] Bouhnik $\mathrm{AD}$, Preau $\mathrm{M}$, Lert $\mathrm{F}$, et al. Unsafe sex in regular partnerships among heterosexual persons living with HIV: evidence from a large representative sample of individuals attending outpatients services in France (ANRS-EN12-VESPA Study). AIDS 2007; 21(Suppl 1): S57-62.

[10] Moatti JP, Prudhomme J, Traore DC, Juillet-Amari A, Akribi HA, Msellati P. Access to antiretroviral treatment and sexual behaviours of HIV-infected patients aware of their serostatus in Cote d'Ivoire. AIDS 2003; 17(Suppl 3): S69-77.

[11] Wolf K, Young J, Rickenbach M, et al. Prevalence of unsafe sexual behavior among HIV-infected individuals: the Swiss HIV Cohort Study. J Acquir Immun Defic Syndr 2003; 33(4): 494-9.

[12] Guimarães M, Grinsztejn B, Chin-Hong $\mathrm{P}$, et al. Behavior surveillance: prevalence and factors associated with high-risk sexual behavior among HIV-infected men in Brazil in the postHAART era. AIDS Behav 2008; 12(5): 741-47.

[13] Kalichman SC. Psychological and social correlates of high-risk sexual behaviour among men and women living with HIV/AIDS. AIDS Care 1999; 11(4): 415-27.

[14] Moatti J, Prudhomme J, Traore D, et al. Access to antiretroviral treatment and sexual behaviours of HIV-infected patients aware of their serostatus in Cote d'Ivoire. AIDS 2003; 17: S69.

[15] Crepaz N, Lyles CM, Wolitski RJ, et al. Do prevention interventions reduce HIV risk behaviours among people living with HIV? A meta-analytic review of controlled trials. AIDS 2006; 20(2): 143-57.

[16] Cohen MS, Chen YQ, McCauley M, et al. Prevention of HIV-1 Infection with Early Antiretroviral Therapy. N Engl J Med 2011; 365(6): 493-505.

[17] Hammer SM. Antiretroviral Treatment as Prevention. New Engl J Med 2011; 365(6): 561-2.

[18] World Health Organization (WHO). Essential prevention and care interventions for adults and adolescents living with HIV in resource-limited settings. Geneva, Switzerland 2008.

[19] Valverde EE, Cassetti I, Metsch LR, et al. Sex risk practices among HIV-positive individuals in Buenos Aires, Argentina. AIDS Patient Care STDS 2009; 23(7): 551-6.

[20] Global Fund. Country Grant Portfolio: El Salvador. Geneva, Switzerland 2011 [cited July 7, 2011].

[21] Family Health International. Behavioral surveillance surveys (BSS) guidelines for repeated behavioral surveys in populations at risk for HIV. Arlington, VA: FHI 2000.

[22] Joint United Nations Programme on HIV/AIDS. Monitoring the Declaration of Commitment on HIV/AIDS, Guidelines on Construction of Core Indicators; 2010 Reporting. Geneva: UNAIDS 2009.

[23] Buchacz K, Greenberg A, Onorato I, Janssen R. Syphilis epidemics and human immunodeficiency virus (HIV) incidence among men who have sex with men in the United States: implications for HIV prevention. Sex Transm Dis 2005; 32(Suppl 10): S73-9.

[24] Jakopanec I, Grjibovski AM, Nilsen O, Aavitsland P. Syphilis epidemiology in Norway, 1992-2008: resurgence among men who have sex with men. BMC Infect Dis 2010; 10(1): 105.

[25] Paz-Bailey G, Meyers A, Blank S, et al. A case-control study of syphilis among men who have sex with men in New York City: association With HIV infection. Sex Transm Dis 2004; 31(10): 581-7.

[26] Sullivan PS, Hamouda O, Delpech V, et al. Reemergence of the HIV epidemic among men who have sex with men in North America, Western Europe, and Australia, 1996-2005. Ann Epidemiol 2009; 19(6): 423-31.

[27] Tabet S, Sanchez J, Lama J, et al. HIV, syphilis and heterosexual bridging among Peruvian men who have sex with men. AIDS 2002; 16(9): 1271-7.

[28] CDC. Primary and secondary syphilis among men who have sex with men--New York City, 2001. MMWR Morb Mortal Wkly Rep 2002; 51(38): 853-6.

[29] CDC. Outbreak of syphilis among men who have sex with men-Southern California, 2000. MMWR Morb Mortal Wkly Rep 2001; 50(7): 117-20. 
[30] CDC. Primary and secondary syphilis--United States, 1998. MMWR Morb Mortal Wkly Rep 1999; 48(39): 873-78.

[31] CDC. Transmission of primary and secondary syphilis by oral sex-Chicago, Illinois, 1998-2002. MMWR Morb Mortal Wkly Rep 2004; 53(41): 966-8.

[32] CDC. Trends in primary and secondary syphilis and HIV infections in men who have sex with men--San Francisco and Los Angeles, California, 1998-2002. MMWR Morb Mortal Wkly Rep 2004; 53(26): $575-8$.

[33] CDC. Internet use and early syphilis infection among men who have sex with men--San Francisco, California, 1999-2003. MMWR Morb Mortal Wkly Rep 2003; 52(50): 1229-32.

[34] Fleming DT, Wasserheit JN. From epidemiological synergy to public health policy and practice: the contribution of other sexually transmitted diseases to sexual transmission of HIV infection. Sex Transm Infect 1999; 75(1): 3-17.

[35] Paz-Bailey G, Teran S, Levine W, Markowitz LE. Syphilis outbreak among Hispanic immigrants in Decatur, Alabama: association with commercial sex. Sex Transm Dis 2004; 31(1): 205.

[36] MSPAS. Medicion de Gastos en SIDA (MEGAS). San Salvador: Programa Nacional De VIH, Ministerio de Salud Publica y Asistencia Social 2006.

[37] MSPAS. Medicion de Gastos en SIDA (MEGAS). San Salvador: Programa Nacional De VIH, Minsiterio de Sald Publica y Asistencia Social 2007.
[38] MSPAS. Medicion de Gastos en SIDA (MEGAS). San Salvador: Programa Nacional De VIH, Minsiterio de Sald Publica y Asistencia Social 2008.

[39] UNGASS. Informe UNGASS 2010, El Salvador. El Salvador: General Assembly Special Session on HIV/AIDS 2010.

[40] Charania MR, Crepaz N, Guenther-Gray C, et al. Efficacy of structural-level condom distribution interventions: a meta-analysis of U.S. and international studies, 1998-2007. AIDS Behav 2011; 15(7): 1283-97.

[41] Luchters S, Sarna A, Geibel S, et al. Safer Sexual Behaviors after 12 Months of Antiretroviral Treatment in Mombasa, Kenya: A Prospective Cohort. AIDS Patient Care STD 2008; 22(7): 587-94.

[42] King R, Katuntu D, Lifshay J, et al. Processes and outcomes of HIV serostatus disclosure to sexual partners among people living with HIV in Uganda. AIDS Behav 2008; 12(2): 232-43.

[43] Simbayi LC, Kalichman SC, Strebel A, Cloete A, Henda N, Mqeketo A. Disclosure of HIV status to sex partners and sexual risk behaviours among HIV-positive men and women, Cape Town, South Africa. Sex Transm Infect 2007; 83(1): 29-34.

[44] Crepaz N, Lyles C, Wolitski R, et al. Do prevention interventions reduce HIV risk behaviours among people living with HIV? A meta-analytic review of controlled trials. AIDS 2006; 20(2): 143.

[45] Fisher JD, Smith L. Secondary prevention of HIV infection: the current state of prevention for positives. Curr Opin HIV AIDS 2009; 4(4): 279-87.

(C) Paz-Bailey et al.; Licensee Bentham Open .

This is an open access article licensed under the terms of the Creative Commons Attribution Non-Commercial License (http://creativecommons.org/licenses/by-nc/ $3.0 /$ ) which permits unrestricted, non-commercial use, distribution and reproduction in any medium, provided the work is properly cited. 